\title{
Complications of LASIK - Therapeutic Refractive Surgery
}

\author{
An Expert Interview with Dan Z Reinstein
}

London Vision Clinic, London, UK

DOI: https://doi.org/10.17925/EOR.2020.14.1.14

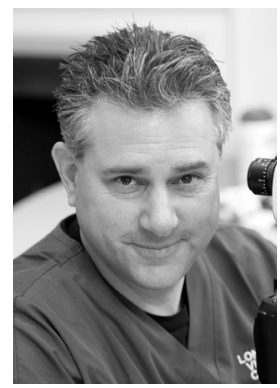

\section{Dan Z Reinstein}

Dan Z Reinstein is the Founder and Medical Director of the London Vision Clinic, and holds Professorships at Columbia University Irving Medical Center, New York; UIster University, UK; and Sorbonne University, France. He created the Carl ZeisS Meditec EDoF PRESBYOND ${ }^{\circledR}$ Laser Blended Vision treatment module for presbyopia, and was a key investigator in developing small incision lenticule extraction (SMILE) His textbook, The Surgeon's Guide to SMILE, was published in April 2018. Prof. Reinstein developed the use of very high-frequency digital ultrasound scanning, now commercialised as Artemis Insight 100 ${ }^{\text {TM }}$ technology and was, in 1991, the first to map the epithelium of the cornea and layered pachymetry. His corneal epithelial mapping research led to both keratoconus screening and extensive applications in therapeutic refractive surgery. Prof. Reinstein is founding editor of the Therapeutic Refractive Surgery section of the Journal of Refractive Surgery and has published over 175 peer-reviewed papers, the majority of which are in the area of corneal imaging and biometry with optical coherence tomography and very high-frequency ultrasound. He was awarded the Waring Medal in 2006, the Kritzinger Award in 2013 and the International Society of Refractive Surgery President's Award and the Senior Achievement Award from the American Academy of Ophthalmology in 2020.

\section{Keywords}

Refractive surgery, complications, laser-assisted in situ keratomileusis (LASIK), photorefractive keratectomy (PRK), night vision disturbances, phototherapeutic keratectomy (PTK), transepithelial phototherapeutic keratectomy (TEPTK), TransPRK, corneal irregularities, topography-guided laser ablation, wavefront-guided laser ablation

Disclosures: Dan Z Reinstein is a consultant for Carl Zeiss Meditec (Carl Zeiss Meditec AG, Jena, Germany) and has a proprietary interest in the Artemis technology (ArcScan Inc, Golden, CO, USA) through patents administered by the Cornell Center for Technology Enterprise and Commercialization (CCTEC), Ithaca, NY, USA.

Review Process: This is an expert interview and, as such, has not undergone the journal's standard peer-review process.

Compliance with Ethics: This article is an expert interview and does not report on new clinical data, or any studies with human or animal subjects, performed by the author.

Authorship: The named author meets the International Committee of Medical Journal Editors (ICMJE) criteria for authorship of this manuscript, takes responsibility for the integrity of the work as a whole, and has given final approval for the version to be published.

Access: This article is freely accessible at tOUchOPHTHALMOLOGY.com

(C) Touch Medical Media 2020

Received: 15 October 2020

Published Online: 4 November 2020

Citation: European Ophthalmic Review. 2020;14(1):14-5

Corresponding Author: Dan Z Reinstein,

London Vision Clinic, 138 Harley Street, London

W1G 7LA, UK. E: dzr@|ondonvisionclinic.com

Support: No funding was received in

the publication of this article.
S urgical techniques for the correction of refractive errors include laser-assisted in situ keratomileusis (LASIK) and surface treatments, such as photorefractive keratectomy (PRK), transepithelial photorefractive keratectomy (TransPRK) and laser epithelial keratomileusis. These have become routine and reliable procedures with extremely high patient satisfaction rates, ${ }^{1}$ with safety, night vision and ocular comfort scores that rival or beat contact lenses. ${ }^{2}$ However, like any surgical procedure, a small percentage of complications can occur. Short-term side effects include delayed visual recovery and dry eye, while potential long-term issues include irregular astigmatism, decentration and, rarely, corneal ectasia. Fortunately, expertise in the management of these complications is now much more prevalent. ${ }^{3,4}$

This year, two of the nine courses selected for presentation at the 38th Congress of the European Society of Cataract and Refractive Surgeons (ESCRS), which took place virtually, were on the subject of therapeutic refractive surgery, with Dan Z Reinstein as course director. In an expert interview, he gives us an overview of these courses.

\section{Q. What courses were you running at this year's ESCRS meeting?}

The first 2-hour didactic course was entitled: 'Therapeutic corneal refractive surgery: achieving excellent outcomes in complications after refractive surgery.' The second was a live 2-hour Grand Rounds-style session, in which ESCRS attendees submitted their complications for the expert panel to discuss.

\section{Q. What is the background to these courses?}

Significant refractive surgery complications are now very unusual; an individual busy surgeon might only have one or two cases a year, and therefore it is difficult for an individual to build up expertise in this area based only on personal experience. Over the last 25 years, a few of us around the world have spent a great deal of our time focussed on this, and have become 'magnets' for our colleagues to send cases to for support. In fact, I only came into refractive surgery as a specialist in the 1990s as a result of my pre-residency bioengineering research at Cornell, where I developed epithelial and layered pachymetric mapping of the cornea.

Even before starting my ophthalmology residency, I was already scanning patients with complications from phase II US Food and Drug Administration (FDA) trials in PRK, referred to the lab by none other than one of the fathers of excimer laser surgery, Steve Trokel, MD. In 1992, I elucidated the cause of the problems encountered with 'central islands', which led VISX to a 'fix' in time to avoid derailing a whole trial. Over the next 10-15, years I scanned corneal complications, initially challenged by even deciphering what it was that I was looking at. If this had been 
100 years ago, it would have been analogous to being the only orthopaedic surgeon with an X-ray!

My move to London and the consulting work that I had started with Carl Zeiss on the MEL ${ }^{\circledR} 80$ (Carl Zeiss Meditec AG, Jena, Germany) in 2001, gave me access to the wavefront-guided and topography-guided tools to approach these complex corneas, for which I could acquire this unique layered diagnostic information. I started the ESCRS course (as well as an American Society of Cataract and Refractive Surgery course) in 1999, with a small handful of indivduals in the audience, and built interest in this field, and the audience now fill a large room, with over 600 attendees for both courses. In 2014, I instigated the Therapeutic Refractive Surgery section of the Journal of Refractive surgery, which was the first of its kind.

\section{Q. Can you give us an overview of the courses?}

For the didactic course, my team from the London Vision Clinic and I offer attendees a session on how to diagnose the problem and how to choose the best therapeutic action. If you have an irregular cornea, how do you know whether to perform wavefront-guided or topography-guided treatment, or a trans-epithelial phototherapeutic keratectomy (PTK)? We discuss the possibility of taking a stepwise approach to repairing the case. We cover subjective and objective tests in the context of obtaining a diagnosis in the various types of complication (small optical zone, decentration, irregular astigmatism, irregularly irregular surfaces etc.). We try to run through the logic of how to plan and perform surgery.

The Grand Rounds 'live' interactive course allows us to demonstrate how to implement these diagnostic and therapeutic approaches. Our faculty includes some of the world's top therapeutic refractive surgeons: Jerry Tan from Singapore, Alex Stojanovic from Norway, Jorge Alió from Spain, and Paolo Vinciguerra from Italy. We can sometimes get into discussions regarding different approaches, but what is interesting is how the panel usually convenes on the same solution once the discussion has taken place. Since the congress this year was in virtual form, each of the faculty presented cases, which were discussed by the rest of the expert panel.

These courses demonstrate how the vast majority of complications can be treated with the currently available technology. We provide insight into the application and interpretation of the different diagnostic technologies currently available, as well as describe the treatment planning process for complex therapeutic refractive surgery cases. These courses are available on the ECSRS website. We also run courses throughout the year, which can be accessed on our website (www.londonvisionclinic.com/courses).

\section{Q. Why is it important to hold these courses?}

Due to the paucity of cases, the need for sophisticated repair technology is not pressing for companies, as these do not become must-have, profit-generating products. Therefore, this is a sector of ophthalmology with no real financial support from the manufacturers, and because it is not driven by industry, it does not get much air-time at meetings. ESCRS has been very responsive, however, to the need, and we are very grateful that the programme committees over the years have adapted the room size as our following grew, and offered better prime-time slots to help increase attendance.

Despite therapeutic refractive surgery being a rarely required modality, it is an extremely important topic because, while it is wonderful for us to provide refractive surgery to patients, to change their lives, we need to be able to provide the back-up care to repair any complications, albeit rare, that may arise..$^{5}$

Solomon KD, Fernandez de Castro LE, Sandoval HP, et al. LASIK world literature review: quality of life and patient satisfaction. Ophthalmology. 2009:116:691-701. Stojanovic A, Suput D. Strategic planning in topography-guided ablation of irregular astigmatism after laser refractive surgery. J Refract Surg. 2005;21:369-76.

Reinstein DZ, Archer TJ, Carp GI, et al. Incidence and outcomes of optical zone enlargement and recentration after previous myopic LASIK by topography-guided custom ablation. J Refract Surg. 2018;34:121-30. Reinstein DZ. Therapeutic refractive surgery: state of technology and a call to action. J Refract Surg. 2018;34:294-5. 